\title{
Mechanisms of greater cardiomyocyte functions on conductive nanoengineered composites for cardiovascular applications
}

This article was published in the following Dove Press journal:

International Journal of Nanomedicine

14 November 2012

Number of times this article has been viewed

\author{
David A Stout ${ }^{1,2}$ \\ Jennie Yoo ${ }^{2}$ \\ Adriana Noemi Santiago- \\ Miranda ${ }^{3}$ \\ Thomas J Webster ${ }^{1,4}$ \\ 'School of Engineering, ${ }^{2}$ Division \\ of Biology and Medicine, Brown \\ University, Providence, RI, ${ }^{3}$ Department \\ of Chemical Engineering, University \\ of Puerto Rico, Mayagües, PR, \\ ${ }^{4}$ Department of Orthopedics, Brown \\ University, Providence, RI, USA
}

Background: Recent advances in nanotechnology (materials with at least one dimension between $1 \mathrm{~nm}$ and $100 \mathrm{~nm}$ ) have led to the use of nanomaterials in numerous medical device applications. Recently, nanomaterials have been used to create innovative biomaterials for cardiovascular applications. Specifically, carbon nanofibers (CNF) embedded in poly(lacticco-glycolic-acid) (PLGA) have been shown to promote cardiomyocyte growth compared with conventional polymer substrates, but the mechanisms involved in such events remain unknown. The aim of this study was to determine the basic mechanism of cell growth on these novel nanocomposites.

Methods: CNF were added to biodegradable PLGA (50:50 PGA:PLA weight ratio) to increase the conductivity, mechanical and cytocompatibility properties of pure PLGA. For this reason, different PLGA to CNF ratios (100:0, 75:25, 50:50, 25:75, and 0:100 wt\%) with different PLGA densities $(0.1,0.05,0.025$, and $0.0125 \mathrm{~g} / \mathrm{mL})$ were used, and their compatibility with cardiomyocytes was assessed.

Results: Throughout all the cytocompatibility experiments, cardiomyocytes were viable and expressed important biomarkers, including cardiac troponin $\mathrm{T}$, connexin-43, and alpha-sarcomeric actin $(\alpha-\mathrm{SCA})$. Adhesion and proliferation experiments indicated that a PLGA density of $0.025 \mathrm{~g} / \mathrm{mL}$ with a PLGA to CNF ratio of 75:25 and 50:50 (wt \%) promoted the best overall cell growth, ie, a 55\% increase in cardiomyocyte density after 120 hours compared with pure PLGA and a $75 \%$ increase compared with the control at the same time point for 50:50 (wt $\%$ ). The PLGA:CNF materials were conductive, and their conductivity increased as greater amounts of CNF were added to pure PLGA, from $0 \mathrm{~S} \cdot \mathrm{m}^{-1}$ for pure PLGA $(100: 0 \mathrm{wt} \%)$ to $5.5 \times 10^{-3} \mathrm{~S} \cdot \mathrm{m}^{-1}$ for pure $\mathrm{CNF}(0: 100 \mathrm{wt} \%)$, as compared with natural heart tissue (ranging from $0.16 \mathrm{~S} \cdot \mathrm{m}^{-1}$ longitudinally to $0.005 \mathrm{~S} \cdot \mathrm{m}^{-1}$ transversely). Tensile tests showed that the addition of CNF increased the tensile strength to mimic that of natural heart tissue, ie, $0.15 \mathrm{MPa}$ for $100 \%$ PLGA to $5.41 \mathrm{MPa}$ for the 50:50 (PLGA to CNF [wt \%: $\mathrm{wt} \%$ ]) ratio at $0.025 \mathrm{~g} / \mathrm{mL}$. Atomic force microscopy indicated that the addition of CNF to PLGA increased the material surface area from 10\% (100:0 [PLGA to carbon nanofiber (wt\%:wt \%)]) to over 60\% (50:50 [PLGA to carbon nanofibers (wt \%:wt \%)]). Lastly, the adsorption of specific proteins (fibronectin and vitronectin) showed significantly more adsorption for the 50:50 PLGA to CNF (wt\%:wt \%) ratio at 0.025 g/mL PLGA compared with pure PLGA, which may be why cardiomyocyte function increased on CNF-enriched composites.

Conclusion: This study demonstrates that cardiomyocyte function was enhanced on 50:50 PLGA to $\mathrm{CNF}$ (wt $\%: \mathrm{wt} \%$ ) composite ratios at $0.025 \mathrm{~g} / \mathrm{mL}$ PLGA densities because they mimicked native heart tissue tensile strength/conductivity and increased the adsorption of proteins known to promote cardiomyocyte function.

Keywords: cardiomyocytes, poly(lactic-co-glycolic acid), carbon nanofibers, nanoroughness, protein adsorption, conductive, nanotechnology
Correspondence: Thomas J Webster Department of Chemical Engineering Northeastern University, Boston, MA 02115, USA

$\mathrm{Tel}+\mathrm{I} 6173736585$

Fax +16173732209

Email th.webster@neu.edu 


\section{Introduction}

Cardiovascular disease is a major epidemic, both in the US and worldwide. Cardiovascular disease refers to a class of diseases that affect the heart and blood vessels of the host, and usually refers to atherosclerosis or arterial disease. ${ }^{1,2}$ Approximately every 25 seconds, an American will have a coronary event, and approximately every minute, someone will die of one. ${ }^{3}$ On average, every 40 seconds, someone in the US has a stroke. ${ }^{3}$ An estimated 74,500,000 adults in the US have hypertension, with approximately $78 \%$ aware of their condition and $68 \%$ using antihypertensive medication, but only $44 \%$ of those treated have their hypertension controlled. ${ }^{3}$ The total direct and indirect costs of cardiovascular disease and stroke in the US for 2010 were estimated at $\$ 503.2$ billion. ${ }^{3}$ In recent years, cardiovascular disease has become the leading killer of American women, surpassing breast cancer. By the time cardiovascular disease has been detected, it is usually fairly advanced, having been developing for decades. ${ }^{4,5}$

Cardiovascular disease is the major culprit when an individual has a myocardial infarction, also known as a heart attack. This usually occurs when a blood vessel in the heart is obstructed in the myocardium and the cardiac muscle surrounding the obstruction dies as a result of oxygen deprivation. This is very important because the myocardium is composed primarily of specialized muscle cells called cardiac myocytes or cardiomyocytes. Although cardiomyocytes comprise only approximately $25 \%$ of the total number of cells in the heart, they account for more than $90 \%$ of the total myocardium volume due to their large size. ${ }^{6}$ Therefore, when a blood vessel in the heart is blocked by an obstruction, known as an infarct, these specialized cells die. Because cardiomyocytes are terminally differentiated cells, they are usually unable to regenerate after an infarction. ${ }^{7}$ Instead, noncontractile fibrous cells gradually begin to replace the dead cardiomyocytes, causing a thin and rigid muscular ventricular wall. ${ }^{8}$ The scar tissue formed reduces contractile function of the heart, causing ventricular remodeling and ultimately leading to heart failure. ${ }^{9}$

Although changes in environmental exposures, reduction in tobacco use, dietary adjustments, and increased physical activity can all improve patient health, the progression of cardiovascular disease is increasing worldwide. New models to detect and treat cardiovascular disease in asymptomatic patients are needed in order to prevent the first symptoms from becoming the last as a result of death. A need for improved and safer approaches to coronary and intracranial revascularization is still required, even with the advances made over the last 10 years.
Unfortunately, no single technology offers the perfect solution. To address these problems, rapid technological advances in cell biology, genomics, and proteomics combined with discoveries in material sciences and bioengineering have created a new field of medicine, known as nanomedicine, which utilizes materials and systems possessing at least one physical dimension between $1 \mathrm{~nm}$ and $100 \mathrm{~nm}$ to construct structures, devices, and systems that have novel properties. ${ }^{10,11}$

The advent of advanced novel nanobiomaterials with improved properties capable of being used in several biomedical applications simultaneously has transformed the field of biomedical research. Nanomaterials are among the most intensively studied materials in a wide range of applications, ranging from fuel cells ${ }^{12,13}$ to nanopatches for the myocardium. ${ }^{14,15}$ These nanostructured composite materials are combinations of at least two constituent materials, a matrix (host) and a reinforcement component (ie, a nanofiller). ${ }^{16}$ It is known that the properties of materials change considerably when the size of constituents is significantly small, within the $1-100 \mathrm{~nm}$ size range. ${ }^{17-19}$ Since these materials have improved physical, chemical, and mechanical properties, they are significantly versatile for a wide range of applications.

One such example is the use of a poly(lactic-co-glycolic acid) (PLGA) material with carbon nanofibers (CNF) embedded to create a "patch" for an infarcted area of the heart. Recent research has shown that when CNF is added to PLGA, cardiomyocytes (specialized heart tissue cells responsible for contraction) will adhere and proliferate better than on their counterparts which are not nano-reinforced, but the mechanism is still largely unknown. ${ }^{15}$

To understand further the function of cardiomyocytes and elucidate a mechanism for such interactions on exposure to PLGA:CNF materials, the purpose of this in vitro study was to alter PLGA density in an effort to shed light on material wettability, protein adsorption, conductivity, tensile strength, and cardiomyocyte function, and to clarify why cardiomyocytes favor some nanocomposites over others. The hypothesis of this study was that materials which mimic the conductivity, tensile strength, and topography of heart tissue itself will maximize cardiomyocyte function.

\section{Materials and methods PLGA:CNF fabrication}

PLGA:CNF composites were fabricated as described in great detail elsewhere. ${ }^{15}$ In brief, different PLGA densities 
(0.1, 0.05, 0.025, and 0.0125 g/mL; 50:50 PLA:PGA wt $\%$, Polysciences, Warrington, PA) were created by dilution in a $50 \mathrm{~mL}$ flask with $30 \mathrm{~mL}$ of tetrahydrofuran (Mallinckrodt Chemicals, St Louis, MO) and sonicated in a B3500ADTHVWR (VWR, Watertown, MA) water bath below $30^{\circ} \mathrm{C}$ for 30 minutes. Next, $500 \mathrm{mg}$ of CNF $(99.9 \%$ by $\mathrm{wt} \%$, Catalytic Materials, Pittsboro, NC) with a diameter of $100 \mathrm{~nm}$ and different lengths from 100 to 200 microns were sonicated (Misonix Sonicator 3000, Cole-Parmer Instrument Company, Vernon Hills, IL) in a $50 \mathrm{~mL}$ beaker with $20 \mathrm{~mL}$ of chloroform (Fisher Scientific, Waltham, MA) at $20 \mathrm{~W}$ for 30 minutes. After obtaining the separately sonicated PLGA and CNF solutions, various PLGA:CNF weight percent ratios were developed (100:0, 75:25, 50:50, 25:75, and 0:100) by adding the appropriate amount of CNF to PLGA in $20 \mathrm{~mL}$ disposable scintillation vials. The CNF weight ratios were measured using a laboratory balance (Mettler Toledo AL54, Fisher Scientific). After the appropriate ratios were formed, each composite material was sonicated (Misonix Sonicator 3000 ) at $10 \mathrm{~W}$ for 20 minutes each.

For ease of experimentation, a $22 \mathrm{~mm}$ diameter microscope cover glass (Fisher Science circles No 1, 0.13-0.17 mm thick; size $22 \mathrm{~mm}$ ) was coated with the aforementioned composite. Before the PLGA:CNF composite was positioned onto the glass substrate, the glass substrate was cleaned via soaking in a 70:30 (vol\%) ethanol deionized solution using an advanced digital shaker (VWR) for 10 minutes. Next, the substrate was added to a $100 \%$ deionized water solution and shaken for 10 minutes.

Using a disposable pipette (Thermo Fisher Scientific, Fair Lawn, NJ), $1 \mathrm{~mL}$ of the appropriate PLGA:CNF composite solution was placed onto the glass substrate and placed into an oven at $42^{\circ} \mathrm{C}$ for 15 minutes. Each composite film was then vacuum-dried (Shel Lab Shellab, Cornelius, OR) at 20 inches of mercury gauge vacuum pressure for 48 hours to allow the tetrahydrofuran and chloroform to evaporate. All the samples and controls were sterilized using ultraviolet light for 24 hours prior to the cell experiments.

\section{Material characterization}

\section{Scanning electron microscopy}

A Hitachi 2700 scanning electron microscope (SEM) was used to characterize the surface of the PLGA:CNF samples at $5 \mathrm{kV}$ utilizing an InLens system and software with magnification ranging from $1000 \times$ to $40,000 \times$.

\section{Atomic force microscopy}

Atomic force microscopy measurements were performed using a scanning probe microscope (Asylum Research,
MFP-3D Coax, Santa Barbara, CA) to create a topographical map of the surface. The analyses were performed in air and under constant applied force (noncontact mode) with a cantilever (Asylum Research) resonant frequency of about $360 \mathrm{kHz}$ and a theoretical spring constant $(\mathrm{k})$ of $42 \mathrm{~N} \cdot \mathrm{m}^{-1}$. Images were processed and analyzed using the Image Processing Data Analysis Igor Pro 6 software (WaveMetrics, Portland, OR). Material surface roughness was evaluated on topographical atomic force microscopy images and the root-mean-square data averaged as well as percent surface area increase (Eq 1) calculated over a series of six images for each sample ratio with the assistance of atomic force microscopy software (WaveMetrics, Igor Pro 6).

$$
\% S A=\frac{\left(A_{F}-A_{l}\right)}{A_{F}} \times 100
$$

where $\% S A$ is the increase in surface area $(\%), A_{F}$ is the final area $(\mathrm{nm})$, and $A_{I}$ is the initial area $(\mathrm{nm})$.

\section{Conductivity}

Conductivity tests were performed to compare material characteristics of the study composite with that of the human myocardium. The electrical resistance of the dry PLGA:CNF samples was obtained by measuring sample resistance while taking geometric considerations into account. Next, $1 \mathrm{~mL}$ of solution was placed on a glass substrate (Fisher Science circles No 1, 0.13-0.17 mm thick; size $22 \mathrm{~mm}$ ) and vacuumdried for 48 hours to evaporate all of the chloroform and tetrahydrofuran. Conductivity measurements were completed using a four-point conductivity theorem (Eq 2). In brief, for a four-point probe measurement, one pair of leads was used to inject the measurement current, while a second pair of leads, in parallel with the first, was used to measure the potential drop across the device. There was no potential drop across the voltage measurement leads, so the contact resistance drop was not included, making for a more accurate system. All measurements were conducted on a four-point conductivity measurement device built inhouse and completed four times on each sample at different locations.

$$
\sigma=\frac{1}{2 \pi V}\left(\frac{1}{l_{1}}+\frac{1}{l_{3}}-\frac{1}{l_{1}+l_{2}}-\frac{1}{l_{2}+l_{3}}\right)
$$

where the $\sigma$ is conductivity $\left(\mathrm{S} \cdot \mathrm{m}^{-1}\right), \pi$ is the number 3.14 , $V$ is voltage $(v), l_{1}$ is the length $(\mathrm{mm})$ between leads 2 and $3, l_{2}$ is the length $(\mathrm{mm})$ between leads 1 and 2 , and $l_{3}$ is the length between 3 and 4 . 


\section{Tensile tests}

Tensile tests were performed to compare material characteristics with that of the human myocardium. A negative flat test sample mold was used to create the material samples, made from Sylgard $184^{\circledR}$ (Dow Corning Inc, Midland, MI) with sample dimensions of gauge length $7.62 \mathrm{~mm}$, width of gauge $3.18 \mathrm{~mm}$, reduced section $9.53 \mathrm{~mm}$, distance between shoulders $26.33 \mathrm{~mm}$, overall length $63.55 \mathrm{~mm}$, width of grip section $9.53 \mathrm{~mm}$, and sample thickness $3.20 \mathrm{~mm}$. Each PLGA:CNF composite ratio solution was added to the mold and vacuum-dried (Shel $\mathrm{Lab}$ ) at 20 inches of $\mathrm{Hg}$ gauge vacuum pressure for 72 hours to allow for solvent evaporation. After the samples were dried and released from the mold, tensile tests were performed in a Rheometric Minimat 2000 tensile machine (Rheometric Scientific, Piscataway, NJ) at a speed of $50 \mathrm{~mm}$ per minute until material failure occurred in accordance with the American Society for Testing and Materials standard test method for tensile properties of plastics designation D638-10. ${ }^{20}$

\section{Protein adsorption}

Adsorption of proteins on the sample surfaces was accomplished using fibronectin and vitronectin. First, all the study samples were rinsed with phosphate-buffered solution ( $8 \mathrm{~g} \mathrm{NaCl}, 0.2 \mathrm{~g} \mathrm{KCL}, 1.5 \mathrm{~g} \mathrm{Na}_{2} \mathrm{HPO}_{4}$, and $0.2 \mathrm{~g} \mathrm{KH}_{2} \mathrm{PO}_{4}$ in $1000 \mathrm{~mL}$ of deionized water adjusted to a $\mathrm{pH}$ of 7.4) twice and placed into cell culture well plates (BD Falcon, Franklin Lakes, NJ) for sterility purposes. Two sets of similar well plates were prepared for each experiment. The first set included $1 \mathrm{~mL}$ of cardiomyocyte growth medium (Celprogen Inc, San Pedro, CA) supplemented with $10 \%$ fetal bovine serum (Thermo Scientific, Waltham, MA). For the second set, $1 \mathrm{~mL}$ of cardiomyocyte growth medium (Celprogen Inc) without fetal bovine serum was added to each well as a control. Both plates were incubated under standard conditions (at $5 \% \mathrm{CO}_{2} 95 \%$ humidified air and $37^{\circ} \mathrm{C}$ ) for 24 hours to allow for protein adsorption. After 24 hours, both plates were taken out, the medium was aspirated, and the samples were rinsed twice with phosphate-buffered solution. The substrate samples were then blocked with $500 \mu \mathrm{L}$ of $2 \%$ bovine serum albumin phosphate-buffered solution for one hour. The bovine serum albumin solution was aspirated and the samples were rinsed twice with phosphate-buffered solution. Next, $500 \mu \mathrm{L}$ of solution containing the first antibody (fibronectin, Chemicon International, Temecula, CA, $3 \mu \mathrm{g}$ antibody in $500 \mu \mathrm{L}$ of $1 \%$ bovine serum albumin solution) was added to each well of both plates and allowed to incubate for one hour under standard conditions of $5 \% \mathrm{CO}_{2}, 95 \%$ humidified air, and $37^{\circ} \mathrm{C}$. After one hour, the antibody solution was aspirated and rinsed with $0.05 \%$ Tween ${ }^{\circledR} 20$ (Sigma-Aldrich, St Louis, MO) three times, each time placed on a table shaker for 5 minutes. After the last Tween 20 aspiration, $500 \mu \mathrm{L}$ of goat antirabbit secondary antibody conjugated with a horseradish peroxidase (Bio-Rad, Hercules, CA) solution $(5 \mu \mathrm{L}$ of secondary antibody in $500 \mu \mathrm{L}$ of $1 \%$ bovine serum albumin solution) was added to each well and incubated for one hour. The secondary antibody was then aspirated and rinsed twice with $0.05 \%$ Tween 20 , each time placed on a table shaker for 5 minutes. All samples were transferred into new well plates and rinsed twice with $0.05 \%$ Tween 20 , each time placed on a table shaker for 5 minutes. Next, $500 \mu \mathrm{L}$ of $2,2^{\prime}$-azino-bis(3ethylbenzothiazoline-6-sulphonic acid (Vector Laboratories Inc, Burlinghame, CA) was added to each well and incubated at room temperature in the dark for 20 minutes. Then, $200 \mu \mathrm{L}$ of each sample was transferred to a 96-well plate and read at $405 \mathrm{~nm}$ using a spectrophotometer. Readings from samples cultured in medium without fetal bovine serum were subtracted from the readings from samples cultured using medium with fetal bovine serum. This procedure was performed again with vitronectin (Chemicon) as the primary antibody. Protein OD readings were normalized to the lowest OD reading, whereas the percent surface area data were not normalized.

Due to changes in surface area between the samples of interest and this study, a unitless variable comparison equation (Eq 3) was established for the amount of protein absorbed onto the substrate surface and surface area percent increases assessed by atomic force microscopy (Eq 1). This allowed for the determination of the protein adsorption capacity for a particular sample with regard to adding CNF and without regard to the surface area of a sample.

$$
\delta=\frac{\% S A}{\rho}
$$

where $\delta$ is the normalized protein adsorption capacity, $\% S A$ is the increase in surface area, and $\rho$ is the normalized protein reading $(\mathrm{OD})$.

\section{Wettability}

Contact angle measurements were performed using a Krüss EasyDrop system (model DSA20S) with Krüss static and dynamic contact angle software (SW4001). This was done by dropping $3 \mu \mathrm{L}$ of distilled water onto the PLGA:CNF composites and measuring the angle between the surface and water droplet (via software). Four measurements were completed for 
each sample, and were performed in triplicate for each PLGA density and PLGA:CNF (wt\%:wt\%) composite ratio.

\section{Material degradation and $\mathrm{pH}$ readings}

Initial dry samples of interest were weighed $\left(\mathrm{W}_{0}\right)$ and sterilized as previously described for the degradation experiments. Next, all samples were immersed in phosphatebuffered solution and incubated under standard cell culture conditions, ie, $37^{\circ} \mathrm{C}, 5 \% \mathrm{CO}_{2}$, and $95 \%$ air. A glass substrate in phosphate-buffered solution and blank phosphate-buffered solution without substrates were used as a reference and control, respectively. After 21, 28, and 36 days, the samples were removed from phosphate-buffered solution, abundantly rinsed with deionized water to remove soluble inorganic salts, and dried in an air vacuum chamber (Shel $\mathrm{Lab}$ ) at 20 inches of $\mathrm{Hg}$ gauge vacuum pressure and room temperature for 48 hours to reach a constant mass. At each time point, the samples were weighed $\left(\mathrm{W}_{\mathrm{t}}\right)$ and percentage weight loss $\left(\% \mathrm{~W}_{\mathrm{L}}\right)$ with respect to incubation time was calculated (Eq 4). Percent weight loss was normalized to the amount of PLGA in the composites because CNF do not degrade.

$$
\% W_{L}=\frac{\left(W_{0}-W_{t}\right)}{W_{0}} \times 100
$$

where $\% W_{L}$ is the percent weight loss, $W_{\mathrm{O}}$ is the initial dry sample weight (mg), and $W_{t}$ is the final dry sample weight at a specific time point (mg). The $\mathrm{pH}$ of the supernatant buffer was monitored every 3 days during the experiment using a Corning $430 \mathrm{pH}$ meter (Corning Inc) to determine the acidity of the medium throughout the process.

\section{Cardiomyocyte adhesion and proliferation}

For in vitro analysis, human cardiomyocytes (Celprogen) were seeded at a density of $5.0 \times 10^{4}$ cells $/ \mathrm{cm}^{2}$ for the cell adhesion assay and $5.0 \times 10^{4}$ cells $/ \mathrm{cm}^{2}$ for the cell proliferation assay on PLGA:CNF composites in complete growth medium (Celprogen) supplemented with 10\% fetal bovine serum (Thermo Scientific) and a 1\% penicillin-streptomycin mixture (Fisher Scientific). Cells were seeded into 12-well human cardiomyocyte stem cell culture extracellular matrix plates (Celprogen on top of the various PLGA:CNF samples) and $22 \mathrm{~mm}$ microscope cover slips (Fisher Science circles No 1, 0.13-0.17 mm thick; size $22 \mathrm{~mm}$ ) as controls. The samples were incubated for 4 hours for the cell adhesion assay and for 24, 72, and 120 hours for the cell proliferation assay under standard incubation conditions (at $5 \% \mathrm{CO}_{2}, 95 \%$ humidified air, and $37^{\circ} \mathrm{C}$, changing the medium every other day).

3-(4,5-Dimethylthiazol-2-yl)-2,5-diphenyltetrazolium bromide (MTT) CellTiter $96^{\circledR}$ nonradioactive cell proliferation assays (Promega, Madison, WI) were used to analyze the cytocompatibility properties of the composite. A fluorescence research microscope (DM5500B, Leica, Wetzlar, Germany) was used to determine cell attachment and proliferation on the PLGA:CNF samples after the prescribed time period and for comparison with the MTT results. At the end of each experiment, the samples were rinsed with phosphate-buffered solution and saturated with $10 \%$ buffer formalin acetate (Fisher Scientific) for 15 minutes. For this, the samples were again rinsed with phosphate-buffered solution twice and then dyed with 4'-6diamidio-2-phenylindole dihydrochloride (DAPI, Molecular Probes, Eugene, OR). The samples were rinsed again and stored in phosphate-buffered solution for imaging. Samples were immediately imaged and counted, four images per sample, using a $10 \times$ objective lens.

The optical density (OD) data for the cardiomyocyte MTT assays were plotted as the mean \pm standard error of the mean, and standard curve analysis for OD and total cell counts. For DAPI staining, the cardiomyocyte count was determined in at least five randomly chosen microscope fields (magnification 10×) for each sample.

\section{Cardiomyocyte viability}

To assess cell viability, the cells were seeded into 12 -well plates (BD Falcon) with each sample ratio and a control glass substrate at $5.5 \times 10^{4}$ cells $/ \mathrm{mL}$, and incubated for 24,72 , and 120 hours under standard incubation conditions. A Live/Dead ${ }^{\circledR}$ viability/cytotoxicity assay kit for mammalian cells (Molecular Probes) was used to assess cell viability and morphology qualitatively. The LIVE/DEAD assay is a two-color assay simultaneously staining with green fluorescent calcein AM indicating intracellular esterase activity and red fluorescent ethidium homodimer-1 indicating loss of plasma membrane integrity. The medium was removed from each well, and the samples were washed with phosphate-buffered solution. The cells were then incubated for 30 minutes with a $500 \mu \mathrm{L}$ solution containing $2 \mu \mathrm{M}$ calcein AM and $4 \mu \mathrm{M}$ ethidium homodimer-1 dissolved in phosphate-buffered solution and imaged using a fluorescence microscope (Zeiss, Axiovert 200M, Oberkochen, Germany). Samples were immediately imaged and counted, with four images per sample. 


\section{Cardiomyocyte immunofluorescence staining}

To indicate cellular specificity towards normal cardiomyocyte characteristics, seeded cells were immunofluorescently stained with cardiomyocyte-specific biomarkers to demonstrate integrity of the cells, ie, connexin-43 for gap junction channels, $\alpha$-SCA for cardiac myocytes, and cardiac troponin T for contractile myocytes. ${ }^{21}$ Cardiomyocytes are interconnected by gap junction channels conducting electrical impulses and direct intercellular signaling. ${ }^{22}$ Connexin- 43 is one of the three proteins that comprise the channels. $\alpha$-SCA is considered to be a specific protein found only in alpha skeletal and alpha cardiac muscle actin in cardiomyocytes..$^{23}$ Troponin $\mathrm{T}$ is part of the troponin complex that binds to actin in thin myofilaments, indicating the contractility of cardiomyocytes.

Cells were seeded into 12-well plates (BD Falcon) with each sample and a control glass substrate at $5 \times 10^{4}$ cells $/ \mathrm{mL}$, and were incubated under standard incubation conditions for 120 hours. The medium was then removed and cell cultures were rinsed twice with phosphate-buffered solution. Cells were fixed for 15 minutes with $1-2 \mathrm{~mL}$ of $10 \%$ formalin acetate (Fisher Scientific), permeabilized with $0.2 \%$ Triton X-100 (Sigma-Aldrich) diluted in phosphate-buffered solution for 5 minutes, and blocked with Image-iT FX signal enhancer (Invitrogen, Carlsbad, CA) for 30 minutes at room temperature with two phosphate-buffered solution washes in between each step. Primary rabbit polyclonal anticonnexin-43, mouse monoclonal anti- $\alpha$-SCA, and rabbit polyclonal anti-cardiac troponin T antibodies (Abcam, Cambridge, MA) were used at a dilution of 1:400 in phosphate-buffered solution for one hour at room temperature. Secondary Alexa Fluor $488^{\circledR}$-conjugated goat anti-mouse $\mathrm{IgM}$ and anti-rabbit IgG (Invitrogen) were diluted 1:600 in phosphate-buffered solution and incubated for 60 minutes at room temperature. The nucleus was visualized using DAPI (Molecular Probes) stain in a 1:30 dilution for 15 minutes at room temperature. Samples were then mounted with ProLong Gold Antifade (Invitrogen) and imaged with a fluorescence microscope (Axiovert 200M). The images were analyzed using ImageJ software (National Institutes of Health, Bethesda, MD) with the analysis particle tool. The images were converted to an 8-bit color scheme, then adjusted to a red/black threshold and analyzed to measure protein color concentration and compare this with the total area of the image. This was done for all stains.

\section{Statistical analysis}

Cardiomyocyte adhesion and proliferation assays were performed at least in triplicate with three repeats each, and the results were compared with a control glass surface. Analysis of variance software and a Student's $t$-test were used for determining differences between means. A $P$ value $<0.05$ was considered to be statistically significant. For correlation graphs, a curve fitting tool (MathWorks, Natick, MA) in a sigmoidal curve fit with a trust-region algorithm for nonlinear optimization was used. All experiments in this study were performed at least in triplicate, and the results were compared with a control glass surface.

\section{Results \\ Material fabrication}

Representative SEM images of the as-synthesized PLGA:CNF composite surfaces can be seen in Figure 1. CNF were uniformly dispersed within the PLGA matrix and, as expected, more CNF were observed for the higher CNF ratio samples. When looking at the different PLGA densities and similar CNF ratios, uniform CNFs were again uniformly dispersed within the PLGA matrix, suggesting that the materials were properly synthesized (Figure 1).

\section{PLGA:CNF material properties}

\section{Conductivity}

The results of this study also provided evidence that increasing the CNF weight ratio in PLGA increased conductivity, as shown in Figure 2. Conductivity increased as greater amounts of CNF were added to pure PLGA, from $0 \mathrm{~S} \cdot \mathrm{m}^{-1}$ for pure PLGA (100:0 wt $\%)$ to $5.5 \times 10^{-3} \mathrm{~S} \cdot \mathrm{m}^{-1}$ for pure CNF $(0: 100$ $\mathrm{wt} \%$ ), as compared with natural heart tissue (ranging from $0.16 \mathrm{~S} \cdot \mathrm{m}^{-1}$ longitudinally to $0.005 \mathrm{~S} \cdot \mathrm{m}^{-1}$ transversely ${ }^{24}$ ). Clearly, the increased conductivity of the composites was due to the uniform distribution of more conductive CNF within the sample (Figure 1). Therefore, as anticipated, the addition of CNF increased conductivity.

\section{Wettability}

Contact angle experiments suggested that altering the PLGA density did not affect the wettability of the composite. For example, contact angle measurements for a 50:50 [PLGA:CNF (wt\%:wt\%)] sample ranged from $132.0^{\circ}$ for a $0.1 \mathrm{~g} / \mathrm{mL}$ PLGA density to $135.0^{\circ}$ for a $0.0125 \mathrm{~g} / \mathrm{mL}$ PLGA density. Contact angle measurements also suggested that adding CNF made the materials more hydrophobic, as compared with the pure PLGA samples (Figure 2A). For example, pure PLGA for all PLGA densities $(0.1 \mathrm{~g} / \mathrm{mL}, 0.05 \mathrm{~g} / \mathrm{mL}$, $0.025 \mathrm{~g} / \mathrm{mL}$, and $0.0125 \mathrm{~g} / \mathrm{mL}$ ) was $81.0^{\circ} \pm 1.0^{\circ}$, whereas the 75:25 [PLGA:CNF (wt \%:wt $\%$ )] samples were $125^{\circ} \pm 3.0^{\circ}$. This is important because cardiovascular research, 


\section{A}

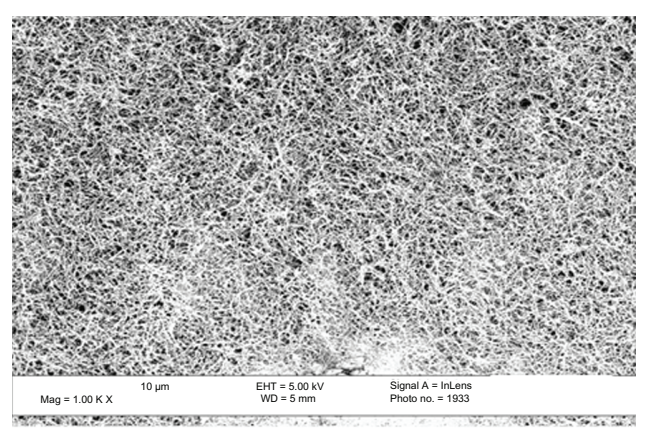

B

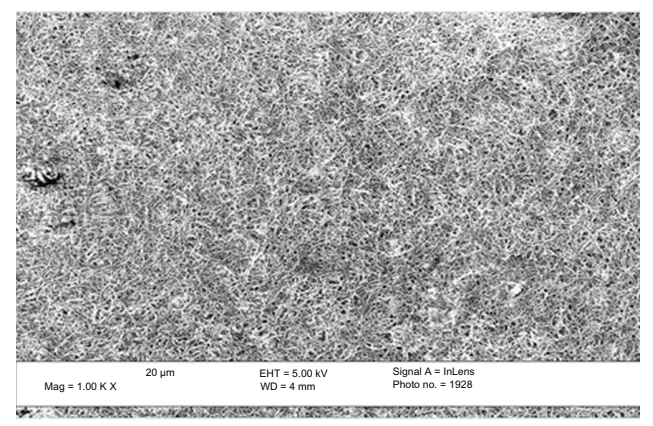

C

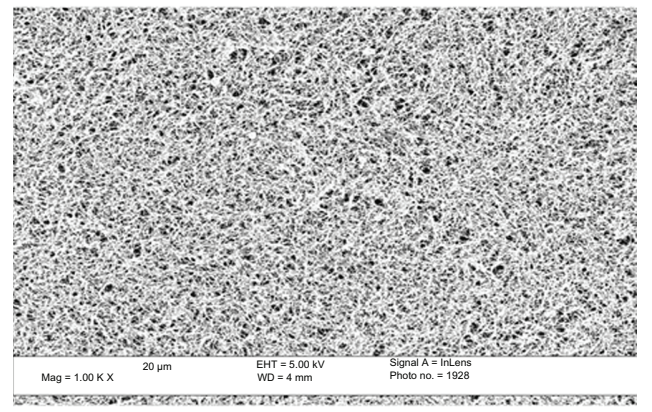

D

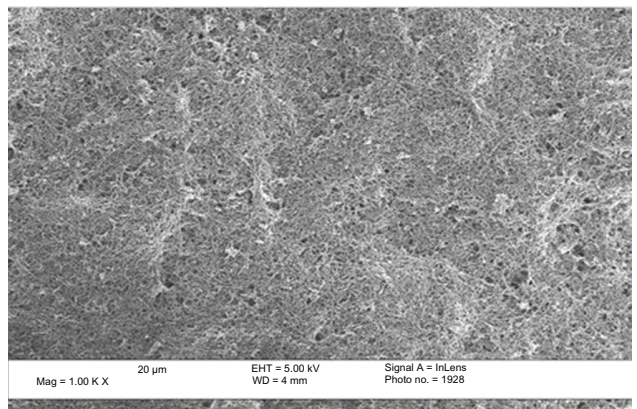

Figure I Scanning electron microscopic images at 5000× magnification showing distribution of CNF fibers in the PLGA matrix at (A) 75:25, (B) 50:50, (C) 25:75, and (D) 0:100 (PLGA:CNF [wt:wt]) at a PLGA density of $0.025 \mathrm{~g} / \mathrm{mL}$.

Note: Scale bar $20 \mu \mathrm{m}$.

Abbreviations: CNF, carbon nanofibers; PLGA, poly(lactic-co-glycolic-acid).

particularly with biomaterials and cardiomyocytes, has shown that when a material is more hydrophobic, protein adsorption will occur more readily than with more hydrophilic materials, and mediate cell attachment and spreading. ${ }^{25}$

\section{Material degradation and $\mathrm{pH}$ readings}

Results of the degradation study showed that the percentage weight loss from pure PLGA was the greatest among all the substrates tested (Figure 3A). As expected, no weight loss
A

\begin{tabular}{|l|l|}
\hline \multicolumn{2}{|l|}{$\begin{array}{l}\text { Contact angle results for } \\
0.025 \mathrm{~g} / \mathrm{mL} \text { PLGA density }\end{array}$} \\
\hline $100: 0^{[\mathrm{a}]}$ & $80.6 \pm 0.4^{\circ}[\mathrm{b}]$ \\
$75: 25$ & $126.9 \pm 1.0^{\circ}$ \\
$50: 50$ & $135.1 \pm 2.1^{\circ}$ \\
$25: 75$ & $135.3 \pm 1.1^{\circ}$ \\
$0: 100$ & $136.2 \pm 0.3^{\circ}$ \\
\hline $\begin{array}{l}\text { [a] PLGA:CNF (wt\%:wt\%) } \\
\text { composite ratio, [b] data are } \\
\text { mean } \pm \text { SD. }\end{array}$ \\
\hline
\end{tabular}

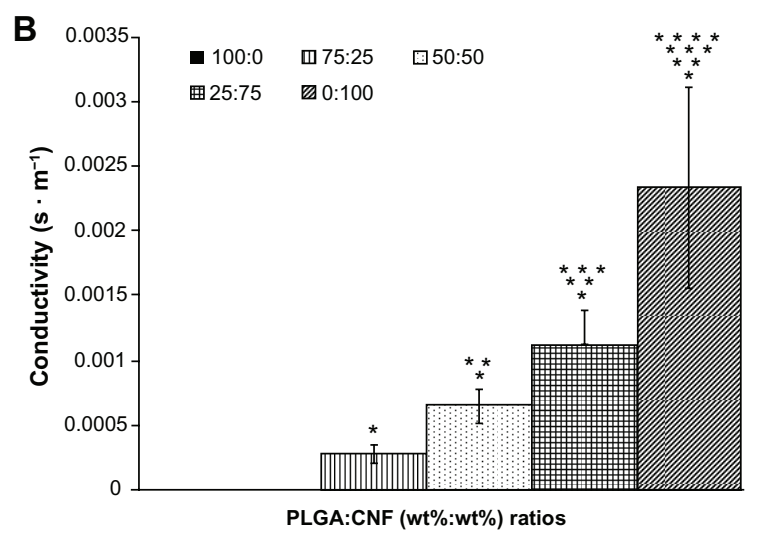

Figure 2 Material characteristics of PLGA:CNF (wt\%:wt\%) looking at (A) wettability of the material at different PLGA density ratios, indicating that all materials are hydrophobic. (B) Example of material conductivity at a PLGA density of $0.025 \mathrm{~g} / \mathrm{mL}$, providing evidence of an inverse relationship between PLGA ratio (wt\%) and material conductivity. Notes: Conductivity data are expressed as the mean \pm standard deviation $(n=3)$. $* \mathrm{P}<0.05$ versus 100:0 (PLGA:CNF [wt\%:wt\%]) ratio; **P $<0.05$ versus (PLGA:CNF [wt\%:wt\%]) ratio; $* * * P<0.05$ versus $50: 50$ (PLGA:CNF [wt\%:wt\%]) ratio, and $* * * * P<0.05$ versus $25: 75$ (PLGA:CNF [wt\%:wt\%]) ratio.

Abbreviations: CNF, carbon nanofibers; PLGA, poly(lactic-co-glycolic-acid).

was observed on pure CNF samples. Specifically, for a PLGA density of $0.025 \mathrm{~g} / \mathrm{mL}$, the weight loss from 75:25 samples was 10\% less that than from pure PLGA, whereas the 50:50 and 25:75 sample ratios [PLGA:CNF (wt\%:wt\%)] had a higher percent weight loss than from pure PLGA after 21 days of incubation. All sample ratios had $25 \%$ or more, which was less than from pure PLGA, at 28 days of incubation; and $30 \%$ or more, which was less than pure PLGA, after 36 days of incubation. This indicates that the dispersion status of CNF in PLGA played an important role in decreasing the degradation behavior of the study composites.

The inhibitory effect of CNF on PLGA weight loss was more significant after longer incubation times, and correlated with the $\mathrm{pH}$ buffering effect of CNF. Specifically, the $\mathrm{pH}$ drop was less than $5 \%$ for all the composites during the first 21 days of incubation, but was approximately $10 \%$ for pure PLGA (Figure 3B). During days 22-36 of incubation, the $\mathrm{pH}$ drop for all the composites and PLGA was faster than during the first 3 weeks of incubation. For a PLGA density of 

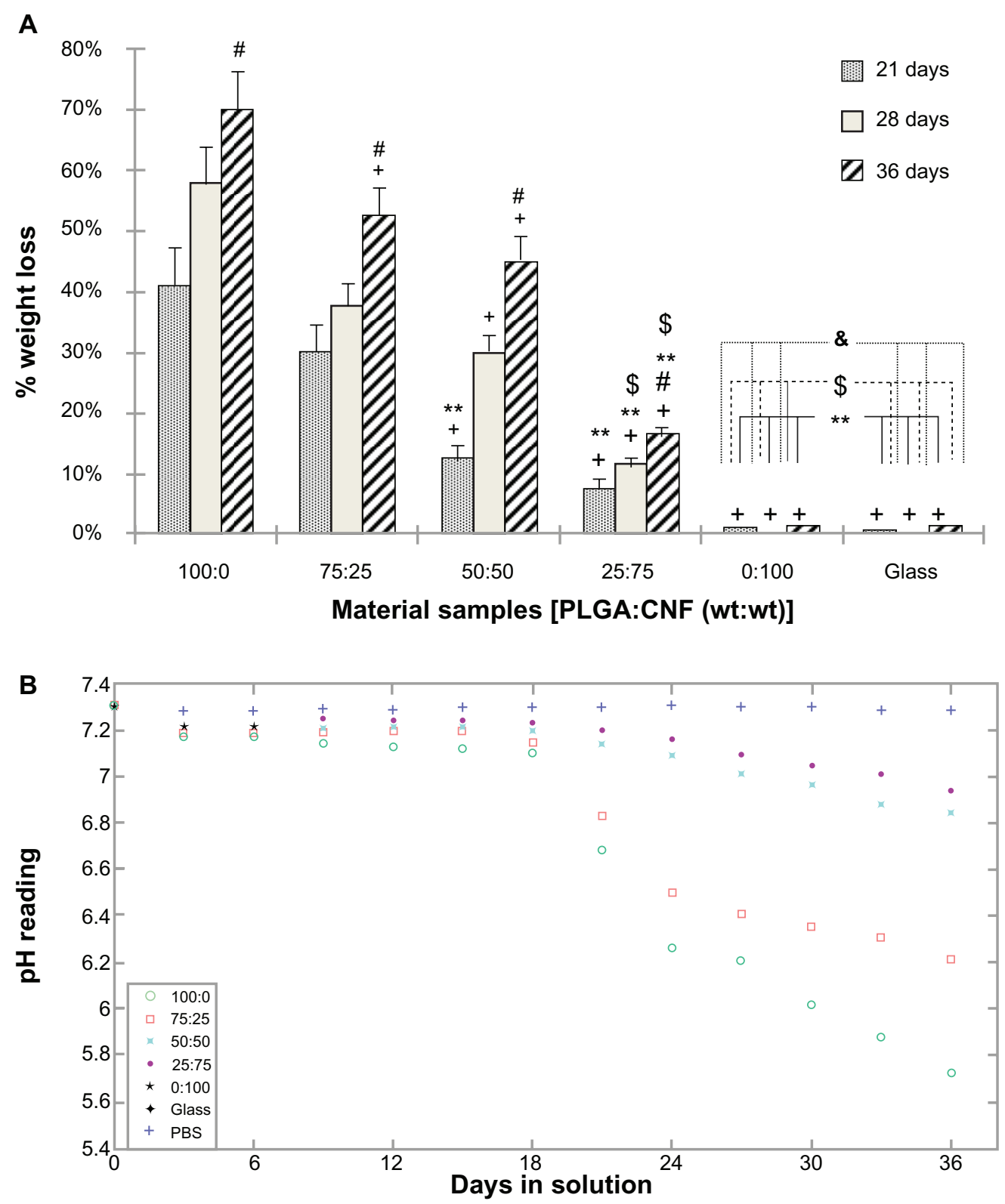

Figure 3 PLGA:CNF material characteristics. (A) Percentage weight loss for 100:0, 75:25, 50:50, 27:75, and 0:100 sample ratios (PLGA:CNF [wt\%:wt\%]) and an etched glass coverslip incubated in phosphate-buffered solution under standard incubation conditions. (B) $\mathrm{pH}$ variation with incubation time for 100:0, 75:25, 50:50, 27:75, and 0:100 sample ratios (PLGA:CNF [wt\%:wt\%]) and an etched glass cover slip incubated in phosphate-buffered solution under standard incubation conditions.

Notes: Values are shown as the mean \pm standard deviation; $n=3 .{ }^{+} P<0.05$ versus PLGA on respective days; ${ }^{*} P<0.05$ versus all composites on respective days; ${ }^{* *} \mathrm{P}<0.05$ versus 75:25 on respective day; ${ }^{\$} P<0.05$ versus 50:50 on respective days, and ${ }^{\circledR} P<0.05$ versus $25: 75$ on respective days.

Abbreviations: CNF, carbon nanofibers; PLGA, poly(lactic-co-glycolic-acid); PBS, phosphate-buffered solution.

$0.025 \mathrm{~g} / \mathrm{mL}$, the $\mathrm{pH}$ drop was $22 \%$ for pure PLGA, and was $15 \%$ for the $75: 25$ ratio [PLGA:CNF (wt $\%: w t \%)$ ], $8 \%$ for the 50:50 ratio [PLGA:CNF (wt $\%: w t \%)$, and only $5 \%$ for the 25:75 ratio [PLGA:CNF (wt \%:wt \%)] after 36 days of incubation. When PLGA degrades, it separates into lactic acid and glycolic acid, which in turn will increase the acidity of the surrounding medium. Therefore, higher $\mathrm{pH}$ readings were observed at higher CNF ratios as compared with pure PLGA samples, due to less PLGA degradation material in the medium.

\section{Tensile tests}

The results show that addition of CNF to the PLGA composite greatly enhanced the composite tensile strength (Figure 4). Specifically, the addition of $25 \%$ CNF (percent total weight) to pure PLGA increased the Young's modulus by over 2500\%, while the addition of $50 \% \mathrm{CNF}$ (percent total weight) increased the Young's modulus by about $3500 \%$ and the addition of $75 \%$ CNF (percent total weight) increased the Young's modulus by about $2100 \%$. Compared with native cardiac heart tissue, the composites had mechanical properties that were stiffer than 


\section{A}

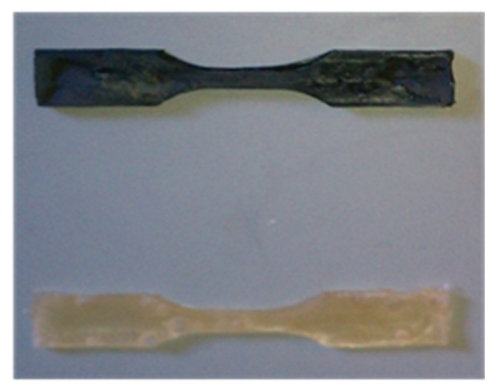

C

\begin{tabular}{|l|l|l|}
\hline \multicolumn{3}{|c|}{ Material characteristics } \\
\hline Sample & $\begin{array}{c}\text { Young's } \\
\text { modulus } \\
(\mathrm{MPa})\end{array}$ & $\begin{array}{l}\text { Elongation at } \\
\text { break (\%) }\end{array}$ \\
\hline $100: 0$ & $0.15 \pm 0.05$ & $131.1 \pm 10.21$ \\
\hline $75: 25$ & $4.05 \pm 0.87$ & $17.80 \pm 3.25$ \\
\hline $50: 50$ & $5.41 \pm 0.74$ & $10.21 \pm 3.24$ \\
\hline $25: 75$ & $3.71 \pm 0.67$ & $4.670 \pm 1.21$ \\
\hline $0: 100$ & 0 & 0.00 \\
\hline
\end{tabular}

B
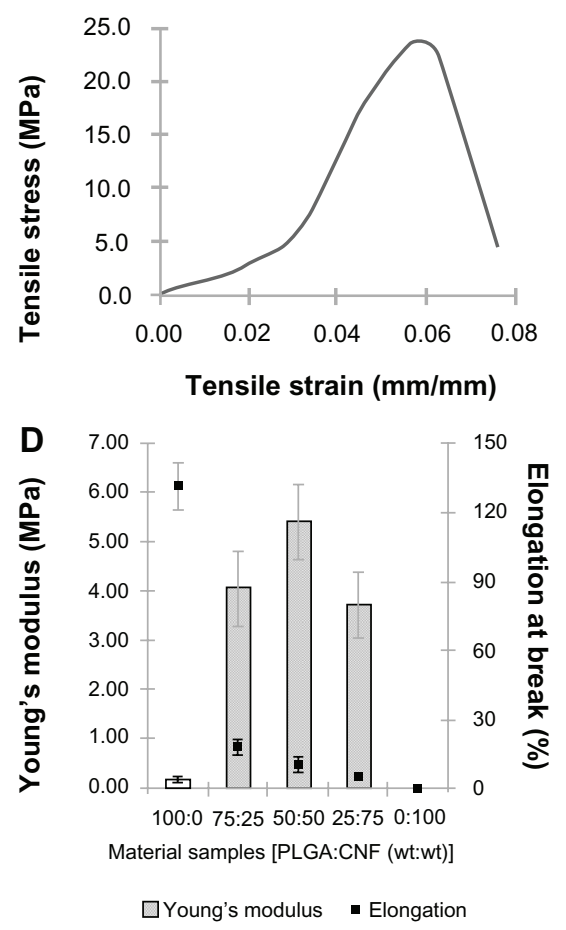

Figure 4 Addition of CNF to PLGA greatly increased the tensile strength and created a material with properties closer to those of normal human myocardium. (A) Photograph of prepared flat test samples. Dimensions of the sample were: gauge length $7.62 \mathrm{~mm}$, width of gauge $3.18 \mathrm{~mm}$, reduced section $9.53 \mathrm{~mm}$, distance between shoulders $26.33 \mathrm{~mm}$, overall length $63.55 \mathrm{~mm}$, width of grip section $9.53 \mathrm{~mm}$, and sample thickness $3.20 \mathrm{~mm}$. (B) Representative stress strain curve graph obtained in tensile experiments used to calculate Young's modulus of a given sample. Stress strain curve of a 25:75 (PLGA:CNF [wt\%:wt\%]) sample ratio with a PLGA density of 0.025 g/mL. (C) Summary of sample ratio material tensile characteristics with a PLGA density of $0.025 \mathrm{~g} / \mathrm{mL}$ as compared with active myocardium. (D) Graphical representation of Young's modulus and percent elongation at break compared with material sample ratios with a PLGA density of $0.025 \mathrm{~g} / \mathrm{mL}$.

Note: Data are shown as the mean count of $n=3$.

Abbreviations: CNF, carbon nanofibers; PLGA, poly(lactic-co-glycolic-acid).

native heart muscle, which is made of collagen and is elastomeric with a stiffness of approximately $50-100 \mathrm{kPa}$ during diastole. ${ }^{26-29}$ However, the modulus of active myocardium during systole is approximately 20 -fold higher, ${ }^{30,31}$ so more closely resembles that of PLGA:CNF composites. These results indicated that the addition of CNF increased the composite tensile strength to mirror better the ability to strengthen the myocardium. On the other hand, the addition of CNF to the PLGA composites decreased the percent elongation at material failure; $86 \%$ for the addition of $25 \% \mathrm{CNF}$ (percent total weight) to $4 \%$ for the addition of $75 \% \mathrm{CNF}$ (percent total weight), thus indicating an inverse relationship between the addition of CNF to PLGA and elongation at failure. This is not surprising given that the continual addition of CNF to a matrix will hinder the ability of PLGA to adhere to CNF and strengthen the material.

\section{Atomic force microscopy and material topography}

Increased topographical features were present throughout the atomic force microscopy results for all materials compared with an etched glass surface. It was shown that adding CNF to the PLGA solution increased the topographical features and also the surface area of the substrate (Figure 4). Specifically, pure PLGA had a 10\% surface area increase compared with an etched glass cover slip of the same dimensions. With the addition of $25 \% \mathrm{CNF}(\mathrm{wt} \%$ ) to PLGA, the surface area increased by $45 \%$. A $50 \%$ CNF (wt $\%$ ) addition to PLGA increased the surface area by approximately $60 \%$. With the addition of $75 \%$ $\mathrm{CNF}(\mathrm{wt} \%$ ) to PLGA and $100 \% \mathrm{CNF}$, a lesser percent surface area increase was observed. Specifically, the addition of $75 \%$ CNF (wt\%) to PLGA increased the surface area by about $28 \%$, whereas $100 \%$ CNF increased the surface area by about $22 \%$. This is mainly because when too many CNF are added to PLGA, significant agglomeration occurs, creating more micro features and fewer nano features, which actually decreases the surface area. Importantly, this indicates that the addition of nanomaterials to a system can increase topographical features, which in turn can increase cell attachment and growth. ${ }^{32}$

\section{Protein adsorption}

The results of this study indicated that addition of CNF to PLGA directly affects initial protein adsorption events. When 
normalized to pure PLGA samples, the OD reading data for both fibronectin and vitronectin, when compared with the atomic force microscopy surface area percent increase, showed significantly greater adsorption of vitronectin and fibronectin onto composites when adding CNF up to 50\% (weight ratio), then a decrease when adding more CNF to the matrix (Figure 5C and D). These results indicate a direct correlation between surface topography and protein adsorption. This is important because protein adsorption has been correlated with the wound healing process. For example, fibronectin is a known chemoattractant for several cell types which play a role in the wound healing process, ${ }^{33}$ including fibroblasts, endothelial cells, and macrophages. In addition, fibronectin generates a scaffold to which other extracellular matrix components can attach. During the healing phase after a myocardial infarction, large amounts of plasma proteins, namely fibronectin, are deposited around the area of necrosis to promote cell attachment and growth ${ }^{34,35}$ within one day of an infarct.
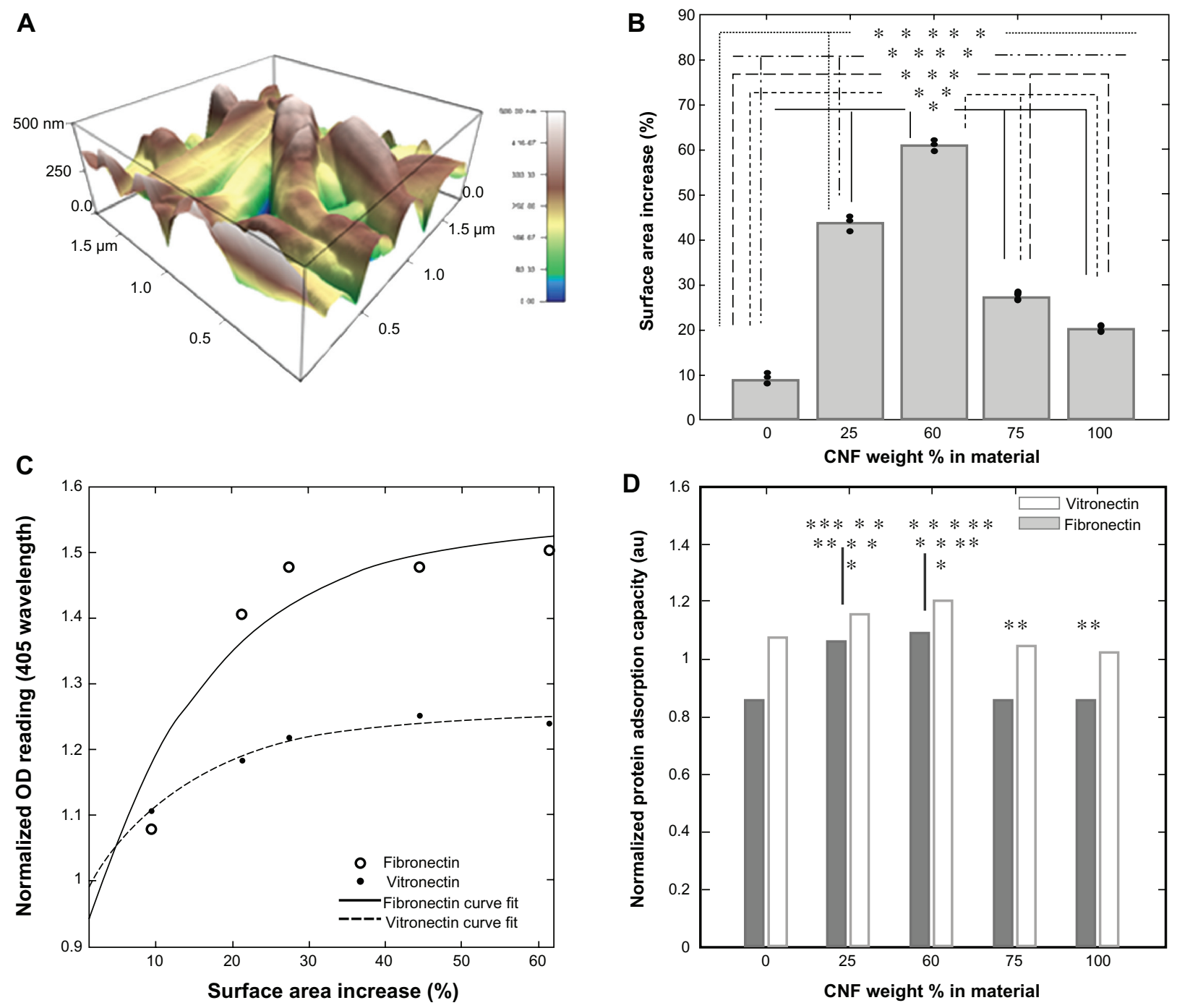

Figure 5 Addition of CNF to the PLGA substrate alters the topography of the material. Using an Asylum MFP three-dimensional atomic force microscope (scan rate I.0 Hz, AC mode with $256 \times 256$ scan points and lines), (A) CNF are shown for a 25:75 ratio (PLGA:CNF [wt\%:wt\%]) sample with a PLGA density of 0.025 g/mL which increases surface nanometer features as well as the total substrate surface area as compared with an etched glass cover slip. (B) It is shown for all PLGA:CNF ratio samples that increasing the CNF weight ratio increased the surface area of the substrate by creating nano, submicron, and micron features. (C) By normalizing the protein adsorption OD readings to the lowest reading (ie, for the controlled etched glass coverslip) and comparing it with the surface area percent increase, the results indicate that protein saturation was around $40 \%-55 \%$ of amount of increase of the surface area, and provide evidence that increasing the surface area (through addition of CNF) allows more proteins to attach to the surface to promote cell attachment. (D) Calculating the normalized protein adsorption capacity indicates that the 75:25 and 50:50 ratios (PLGA:CNF [wt\%:wt\%]) had the highest ability to attach the most proteins to a particular surface, indicating that one of the mechanisms regulating cardiomyocyte interactions is increasing material protein capacity through altering topographical features by addition of CNF.

Notes: This is evident in the similar cardiomyocyte growth trends reported by Stout et al. ${ }^{15} * \mathrm{P}<0.05 \mathrm{CNF}$ wt\% in materials versus $0 \% \mathrm{CNF}$ wt\% in materials; $* * \mathrm{P}<0.05$ CNF wt\% in materials versus $75 \%$ CNF wt $\%$ in materials; ***P $<0.05$ CNF wt\% in materials versus $50 \%$ CNF wt $\%$ in materials; $* * * * P<0.05$ CNF wt $\%$ in materials versus $75 \%$ CNF wt $\%$ in materials, and $* * * * * p<0.05$ CNF wt\% in materials versus $100 \%$ CNF wt $\%$ in materials. Data are shown as the mean count of $n=3$.

Abbreviations: CNF, carbon nanofibers; OD, optical density; PLGA, poly(lactic-co-glycolic-acid). 


\section{Cardiomyocyte compatibility}

For cardiomyocyte adhesion, results from this study showed that, after 4 hours of cell culture, the $0.05 \mathrm{mg} / \mathrm{mL}$ and $0.025 \mathrm{mg} / \mathrm{mL}$ PLGA densities with the 75:25 and 50:50 ratios [PLGA:CNF (wt\%:wt\%)] had the highest cardiomyocyte density. The results of the proliferation assay showed the same trend as that observed during the adhesion assay (Figure 6). Specifically, the 75:25 and 50:50 sample ratios [PLGA:CNF (wt\%:wt\%)] at PLGA densities of $0.05 \mathrm{mg} / \mathrm{mL}$ and $0.025 \mathrm{mg} / \mathrm{mL}$ had the highest cardiomyocyte densities, whereas the 100:0 sample ratio [PLGA:CNF ( $w t \%: w t \%)$ ] for all PLGA densities had the lowest cardiomyocyte densities after 24, 72, and 120 hours. Due to the slower proliferation of the cardiomyocytes compared with other cells (around 72 hours for cell doubling times), one would not see a typical doubling time every 48 hours. Also, Live/Dead images

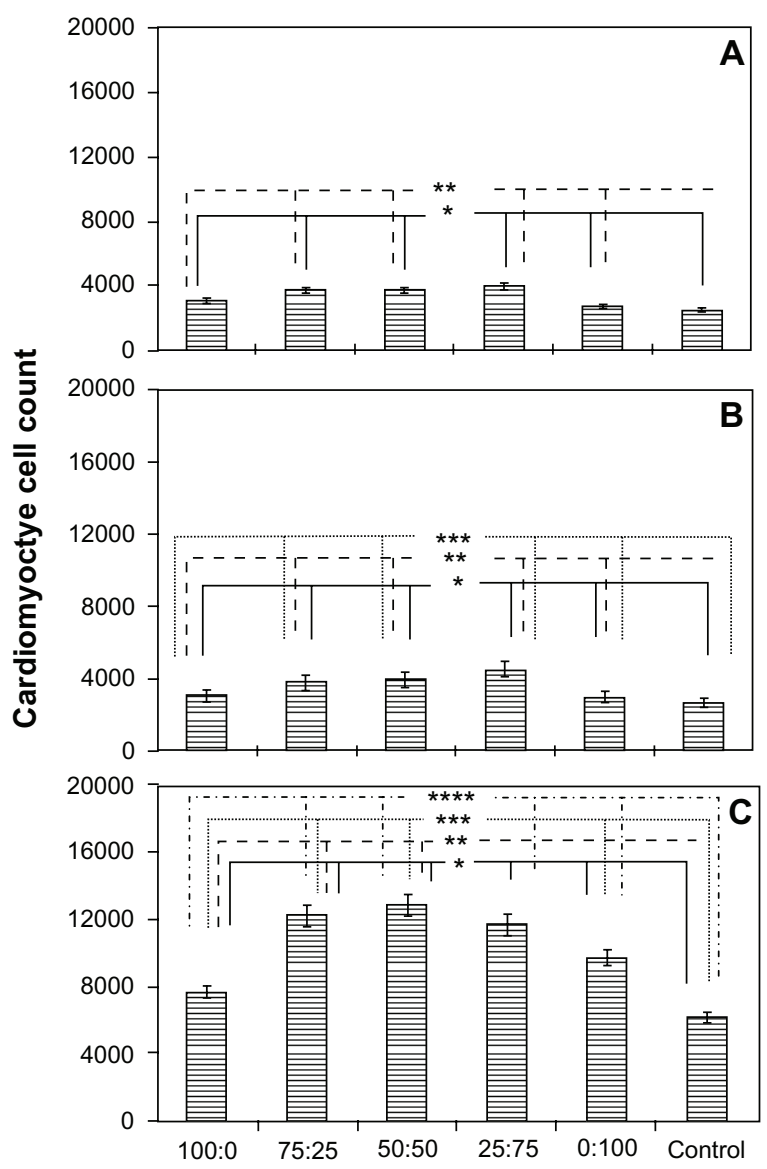

Figure 6 Cardiomyocyte cell proliferation on a PLGA density of $0.025 \mathrm{~g} / \mathrm{mL}$ after (A) 24, (B) 72, and (C) 120 hours on $100 \mathrm{~nm}$ diameter PLGA:CNF composite materials of interest in this study.

Notes: Seeding density was $5 \times 104$ cells $/ \mathrm{cm}^{2}$. Data are shown as the mean count of $\mathrm{n}=3$. The control was the glass substrate. $* \mathrm{P}<0.05$ versus control; $* * P<0.05$ versus similar PLGA:CNF composite ratios and different densities; $* * * P<0.05$ versus similar PLGA:CNF composite ratios between 24 and 72 hours, and $* * * * P<0.05$ versus PLGA:CNF composite ratios between 72 and 120 hours.

Abbreviations: CNF, carbon nanofibers; PLGA, poly(lactic-co-glycolic-acid). showed an increase in cell density over time, with $60 \%-80 \%$ confluence by day 5 for all PLGA:CNF ratios (Figure 7).

Furthermore, immunofluorescence staining of specific cardiac biomarkers (cardiac troponin T, connnexin-43, and $\alpha$-SCA) was conducted in the present study (Figure 8), indicating normal cardiomyocyte activity for all materials. When using ImageJ software, cardiac biomarker staining followed the same patterns showed for all cardiomyocyte adhesion and proliferation experiments (Figure 6). Specifically, 50:50 [PLGA:CNF (wt\%:wt \%)] ratio samples had the highest staining area percentage (63\% for cardiac troponin T, $60 \%$ for connexin- 43 , and $61 \%$ for $\alpha$-SCA) for all cardiac biomarkers. Similarly, cells were observed to have elongated features at all PLGA:CNF ratios. There were no dissimilar morphological features observed among the different weight ratios.

\section{Discussion}

Due to the importance of improved and safer approaches to coronary and intracranial revascularization, many materials, such as alginate ${ }^{37}$ and polytetrafluoroethylene, ${ }^{38}$ have been developed to promote cardiomyocyte function after a myocardial infarction. Research has shown that composite materials composed of different matrices can stabilize heart tissue to decrease the consequences of a myocardial infarction, and such approaches include but are not limited to culturing patient tissue, ${ }^{39,40}$ direct cell injection, ${ }^{41,42}$ and biomaterial scaffolds. ${ }^{43,44}$ Recently, the advent of advanced novel nanobiomaterials with improved properties capable of being used in several biomedical applications simultaneously has transformed the field of biomedical research and the world of cardiovascular biomaterials. One such example is the use of a PLGA material with CNF embedded to create a "patch" for an infarcted area of the heart. The present work addresses the underlying mechanism that alters the material-cell interaction on a novel material and sheds light on cardiomyocyte growth and function, which in turn will help develop alternative bioinspired systems for cardiovascular applications.

Specifically, the addition of CNF to a PLGA solution increased material tensile strength to mimic native heart tissue (approximately $0.5-2.00 \mathrm{MPa}^{30,31}$ ) and increased cardiomyocyte growth. It was shown here that a PLGA density of $0.025 \mathrm{~g} / \mathrm{mL}$ with 75:25 and 50:50 ratios (PLGA:CNF [wt\%:wt\%]) had the highest Young's modulus, and could closely mimic native heart tissue. On the other hand, the 25:75 ratio (PLGA:CNF [(wt\%:wt\%]) was closer to the strength characteristics of native heart tissue, but the material had 

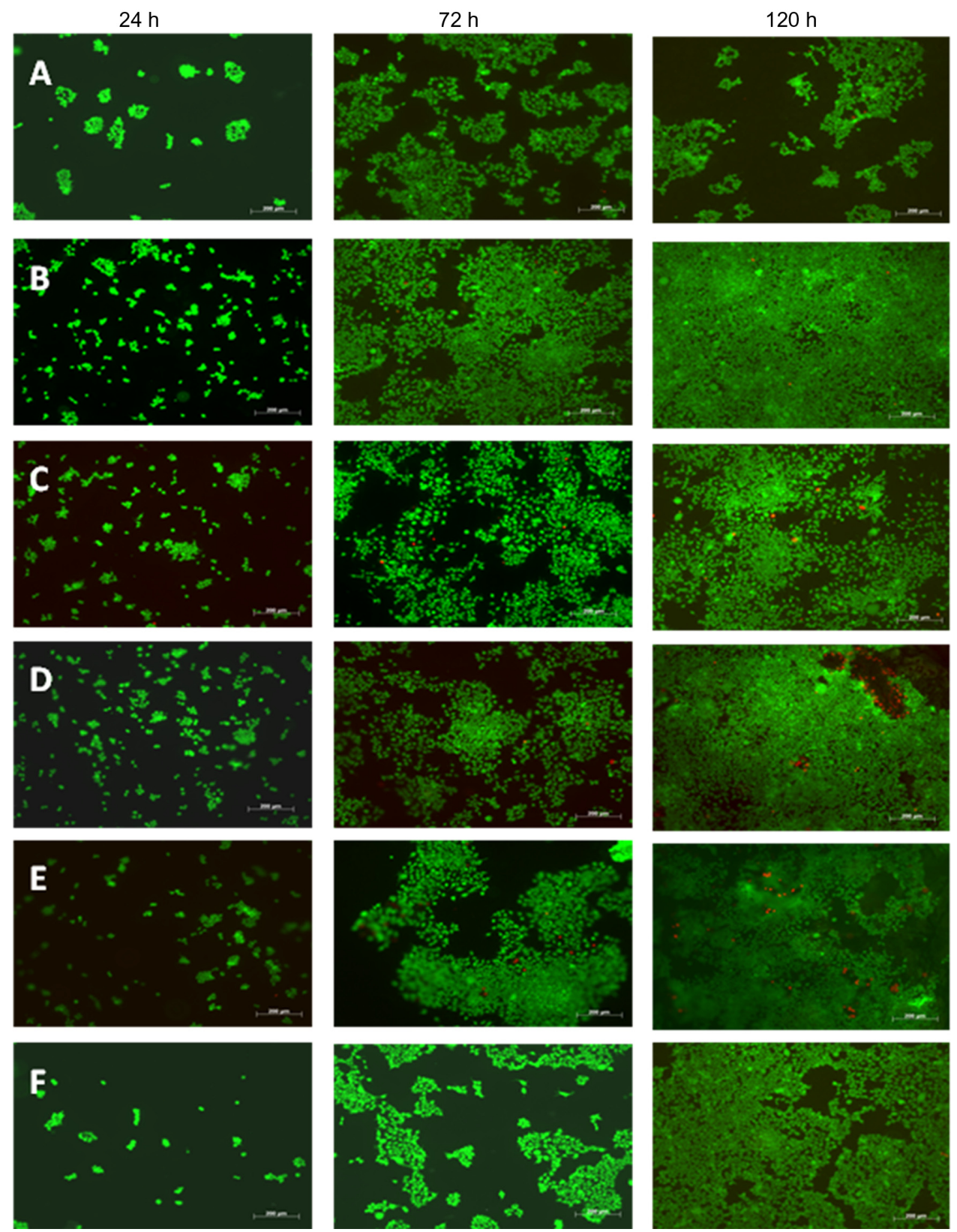

Figure 7 Live/Dead ${ }^{\circledR}$ assay images after 24, 72, and 120 hours on the various weight ratios (A) 100:0, (B) 75:25, (C) 50:50, (D) 25:75, (E) 0:100, and (F) glass with a PLGA density of $0.025 \mathrm{~g} / \mathrm{mL}$.

Note: Green indicates live cells and red indicates dead cells. Seeding density was $5.5 \times 10^{4}$ cells $/ \mathrm{mL}$. Scale bar $200 \mu \mathrm{m}$.

Abbreviation: PLGA, poly(lactic-co-glycolic-acid).

very limited elongation capability (about $2 \%$ at breaking point), and this is very important because native heart tissue is continuously expanding and contracting.

Additionally, adding CNF up to a specific weight ratio (50:50 [PLGA:CNF (wt\%:wt\%)]) increased the surface area, nanoscale roughness, and ultimately vitronectin and fibronectin adsorption capacity (Figure 5). In the past, researchers have found that the adsorption and bioactivity of vitronectin and fibronectin increases on nanophase ceramics and that this enhanced osteoblast function (adhesion, proliferation, and differentiation). ${ }^{45}$ These studies reported that the roughness was closer to the nanometer roughness of bone in nanoceramics, leading to more bone growth on nanophase ceramics. ${ }^{45}$ Even though the myocardium is made up of cardiac muscle, the research here suggests that increasing the nanoroughness of a biomaterial will promote the growth of cardiac-specific muscle, which is parallel to the nanoroughness and increases potential vascular smooth muscle cell and endothelial cell growth. ${ }^{46}$

Clearly, CNF possess nanoscale geometries which imitate the extracellular matrix of various tissues (such as the heart), 

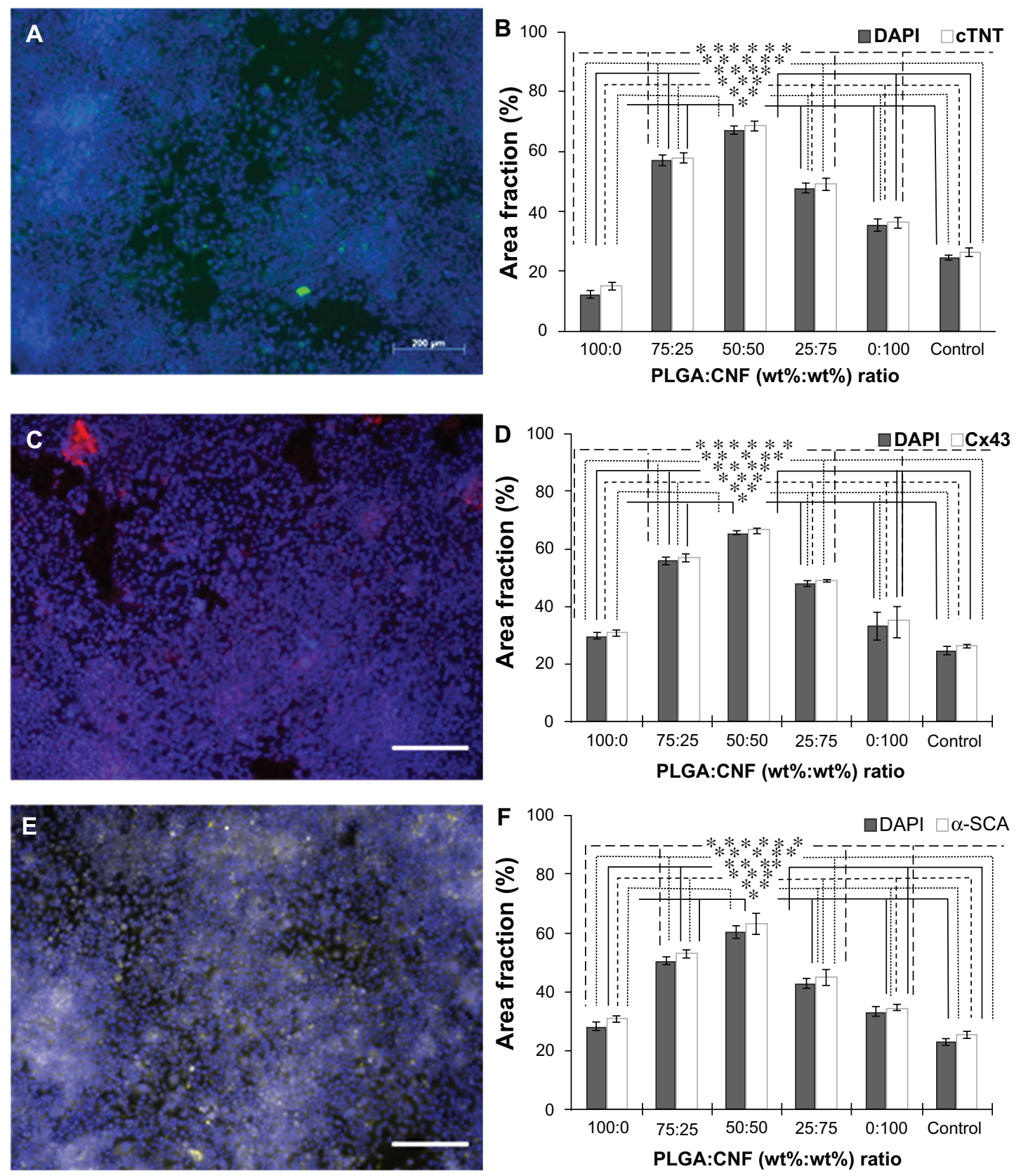

Figure 8 Immunofluorescence staining for cardiomyocyte biomarkers on a $0.025 \mathrm{~g} / \mathrm{mL}$ PLGA density PLGA:CNF composite after 120 hours of incubation. (A) Cardiac troponin T (green) biomarker with DAPI stain (blue) on a 50:50 (PLGA:CNF [wt\%:wt\%]) sample. (B) Connexin-43 (red) with DAPI stain (blue) on a 50:50 (PLGA:CNF [wt\%:wt\%]) sample. (C) $\alpha$-SCA (yellow) with DAPI stain (blue) on a 50:50 (PLGA:CNF [wt\%:wt\%]) sample within the cardiomyocytes, indicating cardiomyocyte activity on the materials. Seeding density was $5.5 \times 10^{4}$ cells $/ \mathrm{mL}$. Scale bar $200 \mu \mathrm{m}$. Area fraction (\%), area of stain on the surface compared with the total area of image, of DAPI (nucleus) and (B) cardiac troponin T, (D) connexin-43, and (F) $\alpha$-SCA after 120 hours of cell incubation, on all PLGA:CNF (wt\%:wt\%) ratio samples.

Notes: The results indicate trends similar to those of the adhesion and proliferation experiments (Figure 6), thus verifying those results and indicating cardiomyocyte activity on the materials. Seeding density was $5.5 \times 10^{4}$ cells/mL. Data are shown as the mean count of $n=3$. Control was glass substrate. $* P<0.05$ versus 100:0 (PLGA:CNF [wt\%:wt\%]) ratio sample; **P $<0.05$ versus 75:25 (PLGA:CNF [wt\%:wt\%]) ratio sample; $* * * P<0.05$ versus 50:50 (PLGA:CNF [wt\%:wt\%]) ratio sample; $* * * * P<0.05$ versus 25:75 (PLGA:CNF [wt\%:wt\%]) ratio sample; ******P $<0.05$ versus $0: 100$ (PLGA:CNF [wt\%:wt\%]) ratio sample, and $* * * * * * p<0.05$ versus control sample.

Abbreviations: CNF, carbon nanofibers; cTNT, cardiac Troponin-T; PLGA, poly(lactic-co-glycolic-acid).

leading to improved cytocompatibility of these materials. This correlates directly with the topography of PLGA:CNF composites which can control protein adsorption events via changes in surface energy (Figure 5C and D). Importantly, it is also known that a material can be too rough and can hinder cellular activity. ${ }^{32}$ For example, Yang et al used diamond films with nanometer and micron scale topographies fabricated by microwave plasma-enhanced chemical vapor deposition and hydrogen plasma treatment, and showed that microsized diamond topographies decreased osteoblast cell 
adhesion and proliferation compared with nanosized diamond topographies. ${ }^{32}$

In addition, we were able to show that when adding $\mathrm{CNF}$ to PLGA, the composite became conductive, whereas the PLGA matrix alone was not conductive. The conductivity values measured in the present work were lower than that of heart tissue (ranging from $0.16 \mathrm{~S} \cdot \mathrm{m}^{-1}$ longitudinally to
$0.005 \mathrm{~S} \cdot \mathrm{m}^{-1}$ transversely), ${ }^{24}$ but future techniques (such as $\mathrm{CNF}$ alignment) may increase anisotropic conductivity ${ }^{47}$ to match that of heart tissue. Pedrotty et $\mathrm{al}^{48}$ showed that numerous cardiac cell functions (including adhesion, proliferation, and migration) may be modulated by electrical stimulation, hence required the use of a conductive material in cardiac applications. Mihardja et $\mathrm{al}^{49}$ also demonstrated that enhanced
A

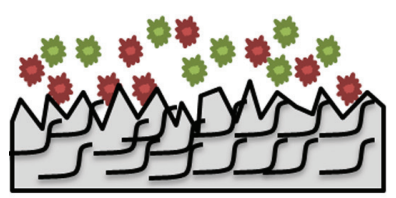

Nanorough stiff substrate

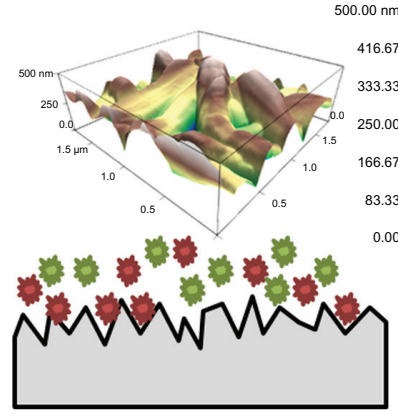

Nanorough substrate
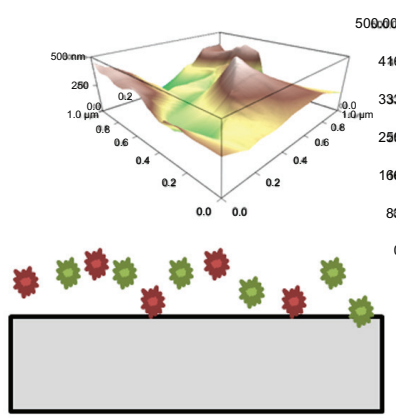

Conventional material

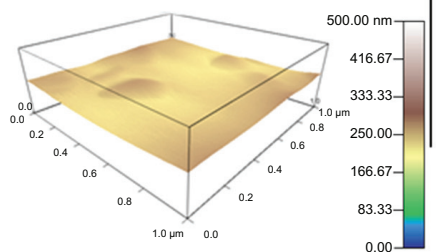

B

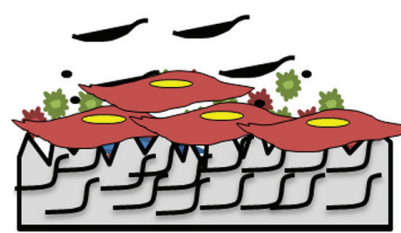

Nanorough stiff substrate

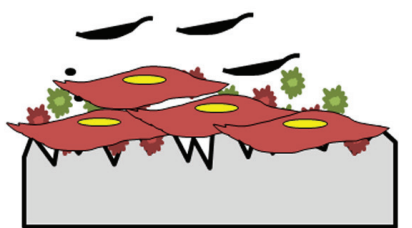

Nanorough substrate

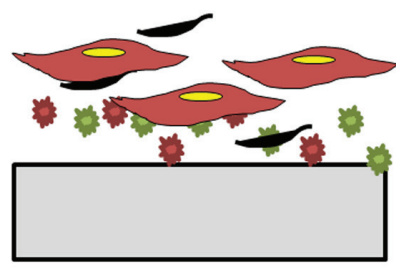

Conventional material
C

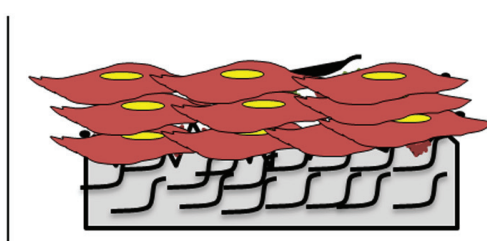

Nanorough stiff substrate

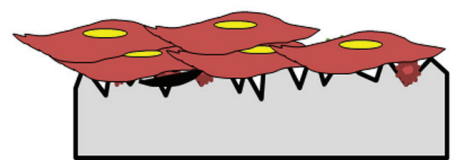

Nanorough substrate

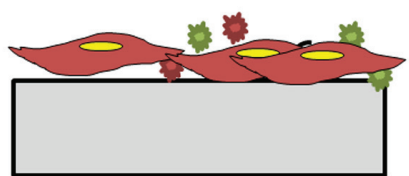

Conventional material

Proteins

Cardiomyocytes

Time

Figure 9 Schematic illustration, with a three-dimensional atomic force microscopy topographical image (scan rate $1.0 \mathrm{~Hz}, \mathrm{AC}$ mode with a $256 \times 256 \mathrm{scan}$ points and lines), of the proposed mechanism by which PLGA:CNF materials may be superior to conventional materials for cardiovascular application. The bioactive surfaces of PLGA:CNF mimic those of the natural myocardium (in stiffness) and increasing protein adsorption capacitance to promote greater amounts of protein adsorption (A) and efficiently stimulate cardiomyocyte growth better than conventional materials and plain nanorough surfaces (B and C). (A) Once a patch is placed into its host, protein adsorption begins on substrates immediately. (B) Cardiomyocyte attachment and growths begins. (C) Due to mimicking the native myocardium (in stiffness) and ability to increase protein adsorption capacitance, more cardiomyocytes adhere and grow on nanorough stiff material as compared with conventional and plain nanorough materials. Abbreviations: CNF, carbon nanofibers; PLGA, poly(lactic-co-glycolic-acid). 
myocardial repair following an ischemic injury could be achieved using conductive polymers, such as polypyrrole. The increasing conductivity of a material with greater $\mathrm{CNF}$ ratios has the potential to propagate electrical signals from contraction of native heart tissue to reduce arrhythmias. Additionally, cell experiments showed the expression of cardiac differentiation markers (cardiac troponin T, connexin-43, and $\alpha$-SMA) as confirmed by fluorescence microscopy, thus indicating normal cardiomyocyte function.

Interestingly, when combining protein adsorption capacity, surface area percent increases, and tensile testing, all results point to either the $75: 25$ or a $50: 50$ material ratio (PLGA:CNF [wt\%:wt\%]) as the best composites for cardiomyocyte growth, which correlates with previous published results. ${ }^{15}$ This research provides the first evidence that addition of CNF to PLGA can increase nanosurface roughness, which increases material surface area without altering wettability, to increase vitronectin and fibronectin adsorption capacity, while at the same time generating tensile strength that closely resembles that of native heart tissue, ultimately to alter the interactions between the materials and cardiomyocytes (Figure 9).

When considering our cardiopatch material applications, future in vivo work must look at CNF compatibility after PLGA degradation. Once the cardiopatch is sutured into place, ${ }^{50-52}$ PLGA will begin to degrade and CNF exposure will increase and become embedded into its host, because $\mathrm{CNF}$ are nonbiodegradable. In vitro experiments have revealed that cell-matrix interactions limit cell motility, growth, and full scaffold colonization, ${ }^{53,54}$ and therefore scaffold degradation is highly desirable to allow for cell replacement. Also, research has shown that carbon-based nanotubes and fibers are biocompatible platforms for neuronal growth and cell differentiation. ${ }^{55,56}$ Therefore, our material has the potential to exploit both of these desirable traits in a tissue engineering matrix, ie, PLGA degradation to allow for better cell growth and CNF for cell progress and continual development.

\section{Conclusion}

This present work demonstrates a few underlying mechanisms to elucidate the way in which cardiomyocytes grow on PLGA and CNF composites. As the CNF weight to specific ratios (50:50 was increased [PLGA:CNF (wt\%:wt\%)]), this study found that nanoscale roughness increases to promote vitronectin and fibronectin adsorption and ultimately increase cardiomyocyte growth, as well as increasing tensile and conductivity properties. Additionally, it was determined that a PLGA density of $0.025 \mathrm{~g} / \mathrm{mL}$ at a 50:50 (PLGA:CNF [wt \%:wt \%]) ratio caused the highest cardiomyocyte growth, indicating that the PLGA density can alter cardiomyocyte adhesion and proliferation to a certain degree. Scanning electron micrographs showed uniform CNF dispersion within the PLGA matrix and a close interaction between cardiomyocytes and substrates, while contact angle experiments suggested that changes in wettability did not occur, thus demonstrating that a simple solution-mixing-drying-based synthesis route can be adopted to develop PLGA:CNF hybrid biocomposites over a broad composition range, possessing a uniform distribution of CNF without any clustering. In summary, cardiomyocyte growth on PLGA:CNF composites was enhanced by creating nanotopographical features due to the addition of CNFs which, in turn, increased protein adsorption capacitance, creating a composite which closely resembles native heart tissue.

\section{Acknowledgments}

The authors would like to thank the National Science Foundation Graduate Research Fellowship Program (1058262), the National Science Foundation (DMR-0805172), the Hermann Foundation, and the Leadership Alliance Summer Research Early Identification Program (SR-IEP) for funding and support. The authors would also like to thank Lei Yang (for assistance with analysis of atomic force microscopy data), Jiangdong Deng and Jason Tresback (Harvard University, for assistance with atomic force microscopy), Urlike Mende (for assistance with cardiomyocyte experiments), Geoff Williams (Brown University Leduc Center, for assistance with fluorescence microscopy), and Paul Waltz (Brown University Price Laboratories, for tensile testing). This work was partially performed at the Center for Nanoscale Systems, a member of the National Nanotechnology Infrastructure Network, which is supported by the National Science Foundation (ECS-0335765).

\section{Disclosure}

The authors report no conflicts of interest in this work.

\section{References}

1. Alpert JS, Thygesen K. A call for universal definitions in cardiovascular disease. Circulation. 2006;114(8):757-758.

2. Maton A. Human Biology and Health. Englewood Cliffs, NJ: Prentice Hall; 1993.

3. Lloyd-Jones D, Adams RJ, Brown TM, et al. Executive Summary: Heart Disease and Stroke Statistics - 2010 Update. Circulation. 2010;121(7):948-954.

4. Björn D. Cardiovascular disease risk factors: epidemiology and risk assessment. Am J Cardiol. 2010;105 Suppl 1:3A-9A 
5. Dzau VJ, Antman EM, Black HR, et al. The cardiovascular disease continuum validated: clinical evidence of improved patient outcomes. Circulation. 2006;114(25):2850-2870.

6. Germani A, Di Rocco G, Limana F, Martelli F, Capogrossi MC. Molecular mechanisms of cardiomyocyte regeneration and therapeutic outlook. Trends Mol Med. 2007;13(3):125-133.

7. Laflamme MA, Murry CE. Regenerating the heart. Nat Biotechnol. 2005;23(7):845-856.

8. Cohen S. Rebuilding broken hearts. Sci Am. 2004;291(5):44.

9. Vunjak-Novakovic G, Tandon N, Godier A, et al. Challenges in cardiac tissue engineering. Tissue Eng Part B Rev. 2009;16(2):169-187.

10. Saw SH, Wang K, Yong T, Ramakrishna S. Polymeric nanofibers in tissue engineering. In: Nanotechnologies for the Life Sciences. Weinheim, Germany: Wiley-VCH Verlag GmbH and C, KGaA; 2007.

11. Cappelletti M, Muggleton N, Walsh V. Quantity without numbers and numbers without quantity in the parietal cortex. Neuroimage. 2009;46(2):522-529.

12. Shuangyin W, Noel K, Sanping J, Xin W. Controlled synthesis of dendriticAu@Pt core-shell nanomaterials for use as an effective fuel cell electrocatalyst. Nanotechnology. 2009;20(2):025605.

13. Mu Y, Liang H, Hu J, Jiang L, Wan L. Controllable Pt nanoparticle deposition on carbon nanotubes as an anode catalyst for direct methanol fuel cells. J Phys Chem B. 2005;109(47):22212-22216.

14. Dvir T, Timko BP, Brigham MD, et al. Nanowired three-dimensional cardiac patches. Nat Nanotechnol. 2011;6(11):720-725.

15. Stout DA, Basu B, Webster TJ. Poly(lactic-co-glycolic acid): carbon nanofiber composites for myocardial tissue engineering applications. Acta Biomater. 2011;7(8):3101-3112.

16. Komarneni S. Nanocomposites. J Mater Chem. 1992;2(12): 1219-1230.

17. Chantidis CA. Nanomechanical and nanotribological properties of carbon-based thin films: a review. International Journal of Refractory Metals and Hard Materials. 2010;28(1):51-70.

18. Liu H, Webster TJ. Nanomedicine for implants: a review of studies and necessary experimental tools. Biomaterials. 2007;28(2):354-369.

19. Verma A, Stellacci F. Effect of surface properties on nanoparticle-cell interactions. Small. 2010;6(1):12-21.

20. American Society for Testing and Materials. Standard Test Method for Tensile Properties of Plastics. Vol D638-610. West Conshohocken, PA: American Society for Testing and Materials; 2010.

21. Zheng H-X, Liu S-S, Tian W-M, Yan H-J, Zhang Y, Li Y. A threedimensional in vitro culture model for primary neonatal rat ventricular myocytes. Current Applied Physics. 2012;12(3):826-833.

22. Tribulova N, Shneyvays V, Mamedova L, et al. Enhanced connexin-43 and $\alpha$-sarcomeric actin expression in cultured heart myocytes exposed to triiodo-1-thyronine. J Mol Histol. 2004;35(5):463-470.

23. Carrier L, Boheler K, Chassagne C, et al. Expression of the sarcomeric actin isogenes in the rat heart with development and senescence. Circ Res. 1992;70(5):999-1005.

24. Roberts-Thomson KC, Kistler PM, Sanders P, et al. Fractionated atrial electrograms during sinus rhythm: relationship to age, voltage, and conduction velocity. Heart Rhythm. 2009;6(5):587-591.

25. Christman KL, Lee RJ. Biomaterials for the treatment of myocardial infarction. J Am Coll Cardiol. 2006;48(5):907-913.

26. Engelmayr GC, Cheng M, Bettinger CJ, Borenstein JT, Langer R, Freed LE. Accordion-like honeycombs for tissue engineering of cardiac anisotropy. Nat Mater. 2008;7(12):1003-1010.

27. Jalil J, Doering C, Janicki J, Pick R, Shroff S, Weber K. Fibrillar collagen and myocardial stiffness in the intact hypertrophied rat left ventricle. Circ Res. 1989;64(6):1041-1050.

28. Mirsky I, Parmley WW. Assessment of passive elastic stiffness for isolated heart muscle and the intact heart. Circ Res. 1973;33(2):233-243.

29. Boublik J, Park H, Radisic M, et al. Mechanical properties and remodeling of hybrid cardiac constructs made from heart cells, fibrin, and biodegradable, elastomeric knitted fabric. Tissue Eng. 2005;11(7-8): $1122-1132$
30. Phillips CA, Petrofsky JS. Myocardial material mechanics: characteristic variation of the circumferential and longitudinal systolic moduli in left ventricular dysfunction. J Biomech. 1984;17(8):561-568.

31. Westerhof N, Stergiopulos N, Noble MIM. Snapshots of Hemodynamics: An Aid for Clinical Research and Graduate Education. New York, NY: Springer; 2010.

32. Yang L, Sheldon BW, Webster TJ. The impact of diamond nanocrystallinity on osteoblast functions. Biomaterials. 2009;30(20):3458-3465.

33. Grinnell F. Fibronectin and wound healing. J Cell Biochem. 1984; 26(2):107-116

34. Kent SP. Diffusion of plasma proteins into cells - a manifestation of cell injury in human myocardial ischemia. Am J Pathol. 1967;50(4): 623-637.

35. Casscells W, Kimura H, Sanchez JA, Yu ZX, Ferrans VJ. Immunohistochemical study of fibronectin in experimental myocardial infarction. Am J Pathol. 1990;137(4):801-810.

36. Willems IE, Arends JW, Daemen MJ. Tenascin and fibronectin expression in healing human myocardial scars. J Pathol. 1996;179(3): 321-325.

37. Landa N, Miller L, Feinberg MS, et al. Effect of injectable alginate implant on cardiac remodeling and function after recent and old infarcts in rat. Circulation. 2008;117(11):1388-1396.

38. Krupnick AS, Kreisel D, Engels FH, et al. A novel small animal model of left ventricular tissue engineering. J Heart Lung Transplant. 2002;21(2):233-243.

39. Wei H-J, Chen C-H, Lee W-Y, et al. Bioengineered cardiac patch constructed from multilayered mesenchymal stem cells for myocardial repair. Biomaterials. 2008;29(26):3547-3556.

40. Ramaswamy S, Gottlieb D, Engelmayr GC Jr, et al. The role of organ level conditioning on the promotion of engineered heart valve tissue development in vitro using mesenchymal stem cells. Biomaterials. 2010;31(6):1114-1125.

41. Perin EC, Dohmann HF, Borejevic R, et al. Time course of improvement following stem cell injections in humans with heart failure. $J \mathrm{Am}$ Coll Cardiol. 2004;43(5):A187.

42. Shintani Y, Fukushima S, Varela-Carver A, et al. Donor cell-type specific paracrine effects of cell transplantation for post-infarction heart failure. J Mol Cell Cardiol. 2009;47(2):288-295.

43. Callegari A, Bollini S, Iop L, et al. Neovascularization induced by porous collagen scaffold implanted on intact and cryoinjured rat hearts. Biomaterials. 2007;28(36):5449-5461.

44. Siepe M, Giraud M-N, Pavlovic M, et al. Myoblast-seeded biodegradable scaffolds to prevent post-myocardial infarction evolution toward heart failure. J Thorac Cardiovasc Surg. 2006;132(1):124-131.

45. Webster TJ, Ergun C, Doremus RH, Siegel RW, Bizios R. Specific proteins mediate enhanced osteoblast adhesion on nanophase ceramics. J Biomed Mater Res. 2000;51(3):475-483.

46. Miller DC, Thapa A, Haberstroh KM, Webster TJ. Endothelial and vascular smooth muscle cell function on poly(lactic-co-glycolic acid) with nano-structured surface features. Biomaterials. 2004;25(1):53-61.

47. Bal S. Experimental study of mechanical and electrical properties of carbon nanofiber/epoxy composites. Mater Des. 2010;31(5):2406-2413.

48. Pedrotty DM, Koh J, Davis BH, Taylor DA, Wolf P, Niklason LE. Engineering skeletal myoblasts: roles of three-dimensional culture and electrical stimulation. Am J Physiol Heart Circ Physiol. 2005;288(4): H1620-H1626.

49. Mihardja SS, Sievers RE, Lee RJ. The effect of polypyrrole on arteriogenesis in an acute rat infarct model. Biomaterials. 2008;29(31): 4205-4210.

50. Nicolosi A, Weng Z, Detwiler P, Spotnitz H. Simulated left ventricular aneurysm and aneurysm repair in swine. J Thorac Cardiovasc Surg. 1990;100(5):745-755.

51. Sakamoto Y, Mizuno A, Buckberg GD, Baretti R, Child JS, Fonarrow G. Restoring the remodeled enlarged left ventricle: experimental benefits of in vivo porcine cardioreduction in the beating open heart. J Cardiac Surg. 1998;13(6):429-439. 
52. Cui J, Li J, Mathison M, et al. A clinically relevant large-animal model for evaluation of tissue-engineered cardiac surgical patch materials. Cardiovasc Revasc Med. 2005;6(3):113-120.

53. Lutolf MP, Hubbell JA. Synthetic biomaterials as instructive extracellular microenvironments for morphogenesis in tissue engineering. Nat Biotechnol. 2005;23(1):47-55.

54. Hollister SJ. Porous scaffold design for tissue engineering. Nat Mater. 2005;4(7):518-524.
55. Mattson M, Haddon R, Rao A. Molecular functionalization of carbon nanotubes and use as substrates for neuronal growth. $J$ Mol Neurosci. 2000;14(3):175-182.

56. Hu H, Ni Y, Montana V, Haddon RC, Parpura V. Chemically functionalized carbon nanotubes as substrates for neuronal growth. Nano Lett. 2004;4(3):507-511.
International Journal of Nanomedicine

\section{Publish your work in this journal}

The International Journal of Nanomedicine is an international, peerreviewed journal focusing on the application of nanotechnology in diagnostics, therapeutics, and drug delivery systems throughout the biomedical field. This journal is indexed on PubMed Central, MedLine, CAS, SciSearch $®$, Current Contents $® /$ Clinical Medicine,

\section{Dovepress}

Journal Citation Reports/Science Edition, EMBase, Scopus and the Elsevier Bibliographic databases. The manuscript management system is completely online and includes a very quick and fair peer-review system, which is all easy to use. Visit http://www.dovepress.com/ testimonials.php to read real quotes from published authors.

Submit your manuscript here: http://www.dovepress.com/international-journal-of-nanomedicine-journal 